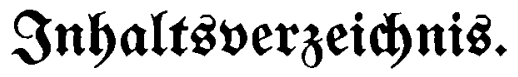

Borwort . . . . . . . . . . . . . . . . . . . . . . III

abtürzungen uno Eiteraturangaben . . . . . . . . . . . . . VIII

Raditrag . . . . . . . . . . . . . . . . . . . . XII

\section{I. $\mathfrak{T} \mathbf{e}$ i .}

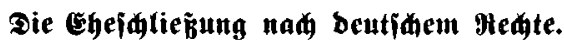

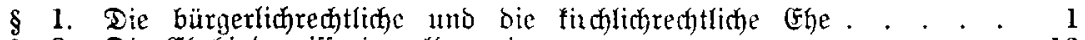

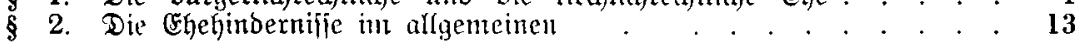

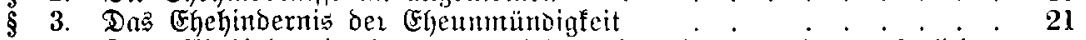

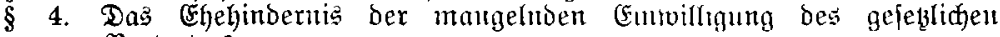
Bertreters . . . . . . . . . . . . 25

§ 5. Das Eghehindernis Der mangchtoen clterlichen Eintwifligung . . . 33

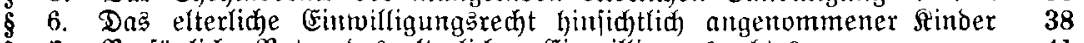

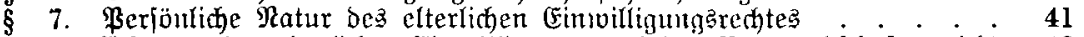

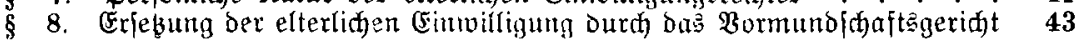

\$ 9. Dả Ehehindernia Der Doppelehe . . . . . . . . . . . . 47

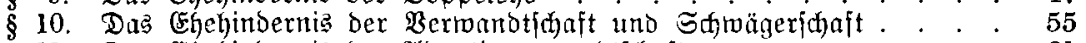

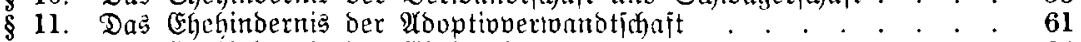

\$12. Das Ehehindernis des Ehebrudy . . . . . . . . . . . . 64

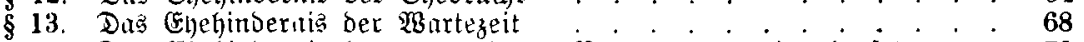

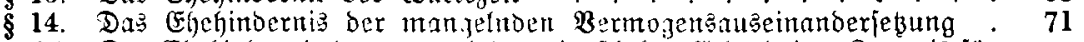

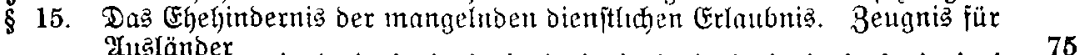

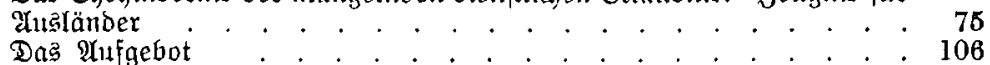

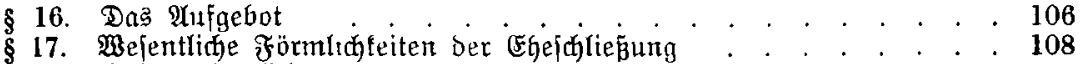

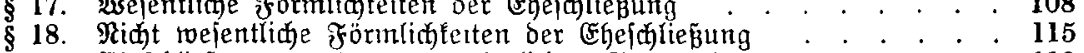

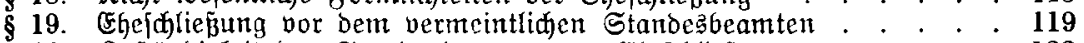

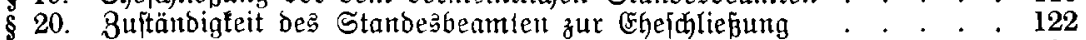

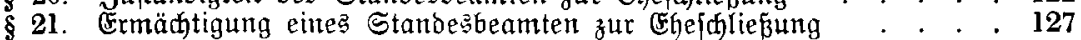

\$22. Bejreiung von Egefindernifien . . . . . . . . . . . . . 130

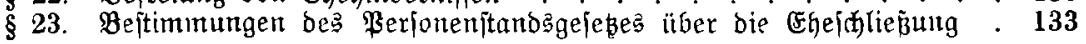

\section{II. $\mathbb{e}$ i r.}

\section{Miditigteit unb Anjedtbarteit ber Ghe.}

§ 24. Nihtigkeit und $\mathfrak{A n f e d f t b a r k e i t ~ d e r ~ E g e ~ i m ~ a l l g e m e i n e n ~ . ~ . ~ . ~ . ~} 167$

\$2. Bründe der Ridtigleit der Éfe . . . . . . . . . . . 173

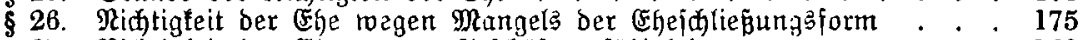

\$ 27. Midhtigfeit ber Ege wegen Bejhäft3unfäfigleit . . . . . . 179

\$28. Mihtigleit ber Ege rogen Doppelehe . . . . . . . . . . 182

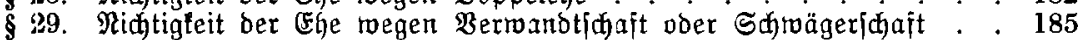

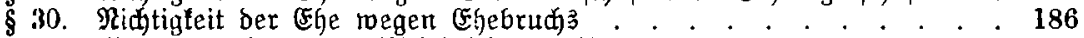

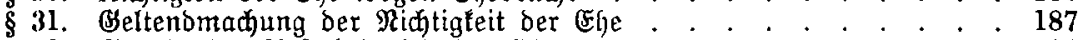

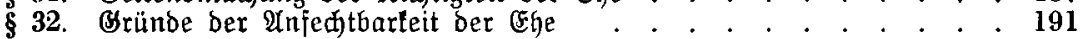

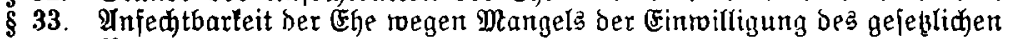
Bertreterz . . . . . . . . . 193

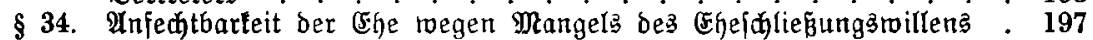

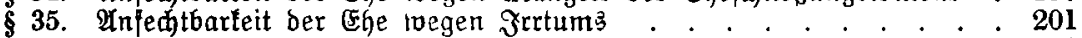

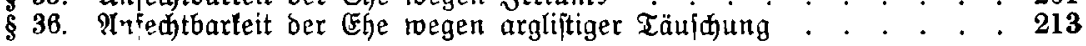


§37. Anfectitbarteit ber She roegen Drohung . . . . . . . . . . 222

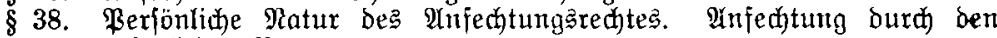
gejebliden Bertreter . . . . . . . . . . . . . 226

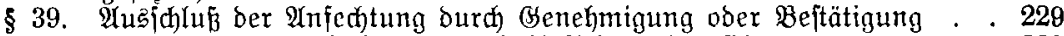

\$ 40. 2)

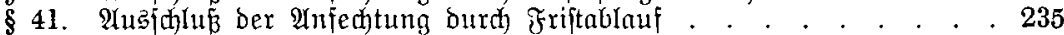

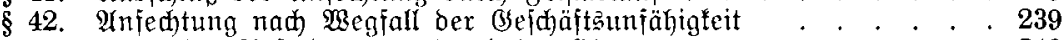

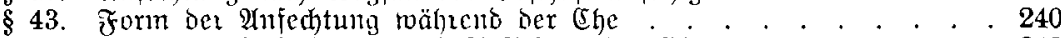

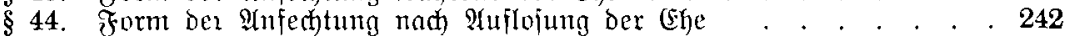

\$ 45. Firfung ber Infectung ber Ehe . . . . . . . . . . . . 247

\$ 46. Whirkutg ber skidhtigfeit Der Cho in Berbältnis zu Drittet . . . . 25I

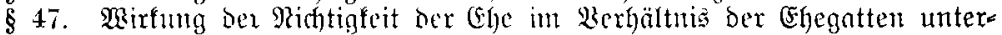
cinanber. Malltedt . . . . . . . . . . . . 253

\section{Il. Wiederverheiratung im salle ber zobesertlärung.}

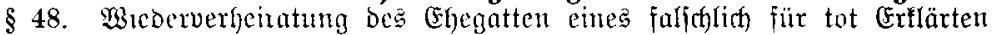

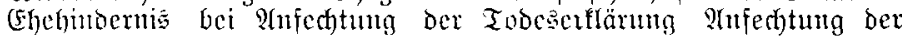
neuen Ehe. Unterhaltamipruth

\section{Teir.}

Juternationale Beítimunngen über bie Cheỉlię̆ung.

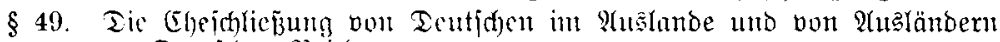
Im Ecutiden Reidfe

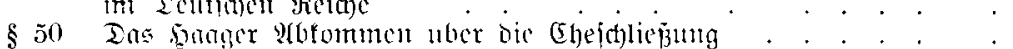

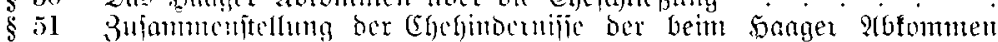
beteilighter Etanten

\section{Eeif.}

כas projefiuale Berfagren it Ghejadhen.

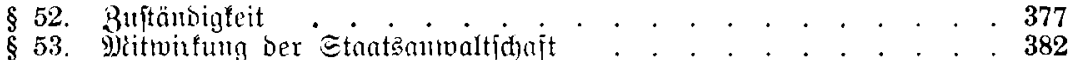

$\$ 54$ छulfutcverfuct . . . . . . . . . . . . . . . 384

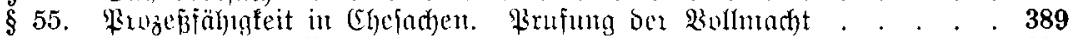

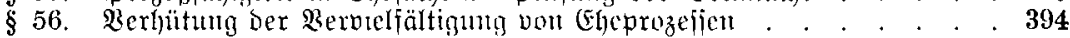

\$5. Bejchränfung ber Berfanolungmaxme . . . . . . . . . . 403

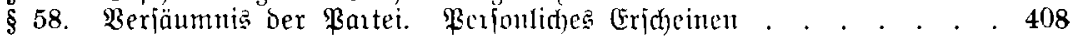

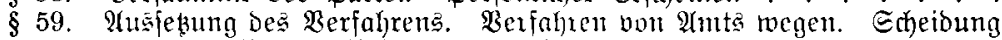

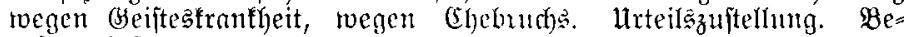
ıufungsinftanz . . . . . . . . . . . . . . . . 414

\$60. Einftreilige Berfügung in Ehejachen : . . . . . 428

§ 61. Tob cints Egegatten. Wirfung des Urteiles. Nitteilung des ltrteiles

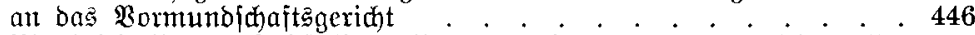

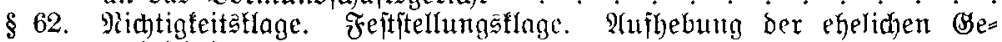
meinjd)aft

\section{Eeir.}

Die Chejueibung nad beutjdem Medte.

§ 63. Die ङheibung ber Ehe im allgemeinen . . . . . . . . . 45I

§ 64. Die Buläffigfeit ber ङheibung . . . . . . . . . . . . . . 458

$\$ 65$. Scheibung wegen (Ehebrud) und ber bemfelben gleidgeftellten itraf= baren מ̣amblungen

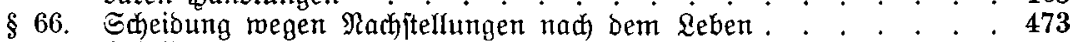

$\S 67$. Sheibung wegen böbliçer Berlajiung . . . . . . . . . . 476

\$68. Scheibung regen tiejer Berrüttung des ehelichen Berhältnifies : . 496

\$ 69. Shbeibung wegen Beifteşfranfheit . . . . . . . . . 536

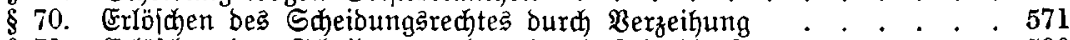

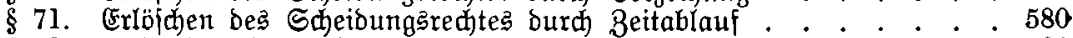

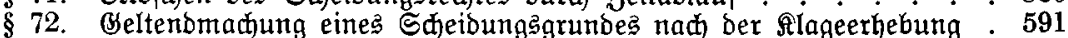

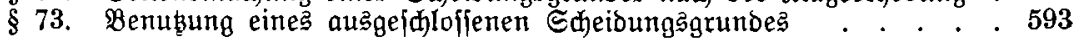




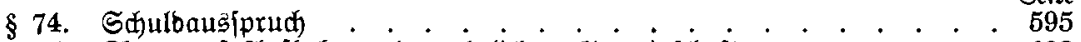

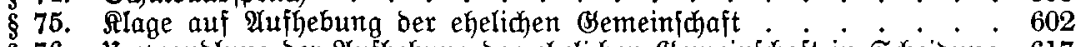

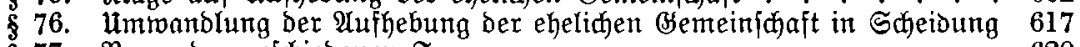

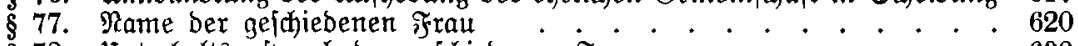

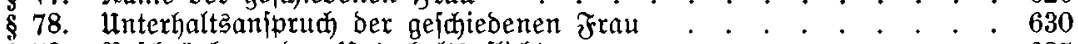

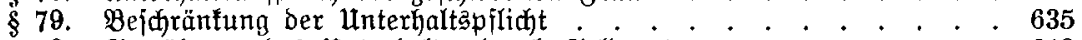

80. Beroührung des Unterhaltes burd ßंeldrente : : : : 640

\$ 81. Unterfaltspfficht bei Biedervergeiratung . : . . . . 644

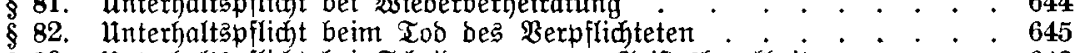

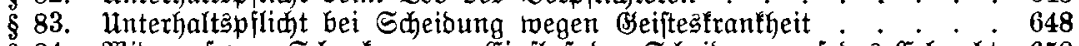

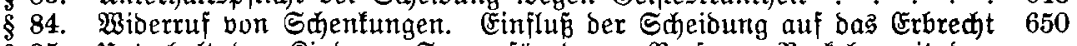

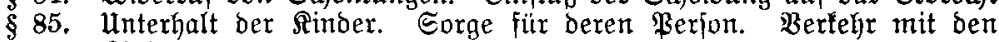
Rindern . . . . . 654

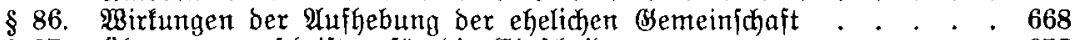

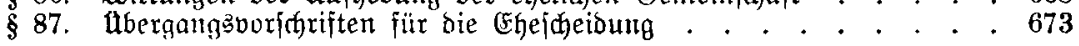

\section{VI. $\mathbb{E}$ i $\mathrm{C}$.}

\section{Jnternationale Beitimmungen iiber bie Gheideioung.}

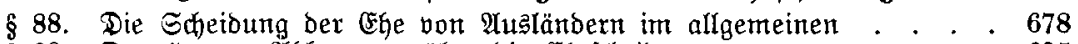

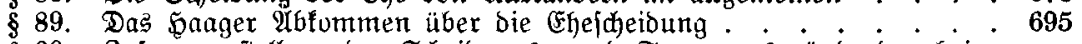

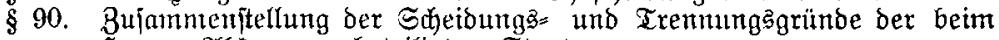
Gaager Arformmen beteiligten Staaten. . . . . . . . 741

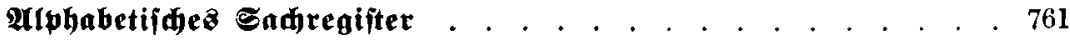

